\title{
Demographic, Clinical Characteristics and Medications of Rehospitalized Patients for Acute Coronary Syndrome: Boomerang Study
}

Tuğba Kemaloğlu Öz', Tarık Kıvrak², Abdallah Almaghraby ${ }^{3}$, Mahmoud Abdelnabi ${ }^{4}$, Onur Taşar ${ }^{5}$, Begüm Uygurr ${ }^{6}$, Emrah Aksakal' ${ }^{7}$, Gobinda Kanti Paul ${ }^{8}$, Seyyad Farshad Sadri ${ }^{9}$, Fatemeh Nikroo ${ }^{9}$, Yagoub Musa ${ }^{10}$, Batur Kanar ${ }^{11}$, Hakkı Kaya ${ }^{12}$, Fady Gerges ${ }^{13}$, Yusuf Çekici ${ }^{14}$, Arash Hashemi ${ }^{15}$, Bilal Çuğlan ${ }^{16}$, Lütffï Bekar ${ }^{17}$, Irina Kotlar ${ }^{18}$, Mustafa Yenerçağ ${ }^{19}$, Mesut Gitmez ${ }^{20}$, Aysel Akhundova ${ }^{21}$, Sinan İnciं22, Mehtap Yeni ${ }^{23}$, Mustafa Doğduş ${ }^{24}$, Meltem Altınsoy ${ }^{25}$, Ayman Helal ${ }^{26}$, Shafa Shahbazova ${ }^{27}$, Fatih Tamnik ${ }^{28}$, Patrick WJ Tiau ${ }^{29}$, İbrahim Ersoy ${ }^{30}$, Fadime Bozdurman ${ }^{31}$, Mehdi Zoghi ${ }^{28}$

'Department of Cardiology, Istinye University and Liv Hospital Ulus, Istanbul, ${ }^{2}$ Department of Cardiology, Firat University, Cardiology, Elazig, Turkey, ${ }^{3}$ Department of Cardiology, University of Alexandria, Alexandria, ${ }^{4}$ Clinical and Experimental Internal Medicine Department, Medical research Institute, University of Alexandria, Alexandria, Egypt, ${ }^{5}$ Department of Cardiology, Elazig State Hospital, Cardiology, Elazig, ${ }^{6}$ Department of Cardiology, University of Health Science Turkey, Istanbul Mehmet Akif Ersoy Thoracic and Cardiovascular Surgery Hospital, Istanbul, 'Department of Cardiology, Regional Training and Research Hospital, Cardiology, Erzurum, Turkey, ${ }^{8}$ Department of Cardiology, Mymensingh Medical College, Cardiology, Mymensingh, Bangladesh, ${ }^{9}$ Department of Cardiology, Asiabak Hospital, Cardiology, Asiabak, Iran, ${ }^{10}$ Department of Cardiology, AlshaabTeaching Hospital, Khatoum, Sudan, ${ }^{11}$ Department of Cardiology, Marmara University, Cardiology, Istanbul,

${ }^{12}$ Department of Cardiology, Çanakkale Onsekiz Mart University, Çanakkale, Turkey, ${ }^{13}$ Department of Cardiovascular sciences,

Mediclinic Al Jowhara hospital, UAE, ${ }^{14}$ Department of Cardiology, Sanliurfa Research and Educational Hospital, Cardiology, Sanliurfa, Turkey, ${ }^{15}$ Department of Cardiology, Erfan General Hospital, Tahran, Iran, ${ }^{16}$ Department of Cardiology, Beykent University,Istanbul, ${ }^{17 D e p a r t m e n t ~ o f ~ C a r d i o l o g y, ~ H i t i t ~ U n i v e r s i t y, ~ C ̧ o r u m, ~}$ Turkey, ${ }^{18}$ Department of Cardiology, University Clinic of Cardiology, Skopje, Macedonia, ${ }^{19}$ Department of Cardiology, University of Health Sciences Samsun Training and Research Hospital, Samsun, ${ }^{20}$ Department of Cardiology, Batman State Hospital, Batman, ${ }^{21}$ Department of Cardiology, Reyap Hospital, Çorlu, ${ }^{22}$ Department of Cardiology, Aksaray University, Aksaray, ${ }^{23}$ Department of Cardiology, Isparta State Hospital, Isparta, ${ }^{24}$ Department of Cardiology, University of Usak Training and

Research Hospital, Usak, ${ }^{25}$ Department of Cardiology, University of Health Sciences Ankara Atatürk Chest Diseases and Chest Surgery Training and Research Hospital, Ankara, Turkey, ${ }^{26}$ Department of Cardiology, Fayoum University, Egypt, ${ }^{27}$ Department of Cardiology, Central Hospital of Baku,Azerbaijan, ${ }^{28}$ Department of Cardiology, Ege University, Cardiology, Izmir, Turkey, ${ }^{29}$ Department of Cardiology, National University of Malaysia, Malaysia, ${ }^{30}$ Department of Cardiology, Afyon Karahisar University of Health Sciences, Afyon, ${ }^{31}$ Department of Cardiology, Samsun Terme Public Hospital, Samsun, Turkey

ORCID:

\author{
Tuğba Kemaloğlu Öz: 0000-0003-1168-8237 \\ Tarkk Kivrak: 0000-0002-5257-4810 \\ Abdallah Almaghraby: 0000-0001-6541-0850 \\ Mahmoud Abdelnabi: 0000-0001-8016-9049 \\ Onur Taşar: 0000-0003-2030-3810 \\ Begüm Uygur: 0000-0003-3998-3713 \\ Emrah Aksakal: 0000-0001-5765-4281 \\ Gobinda Kanti Paul: 0000-0002-1263-353X \\ Seyyad Farshad Sadri: 0000-0003-3301-9405 \\ Fatemeh Nikroo: 0000-0002-5537-606X \\ Yagoub Musa: 0000-0002-4752-4675 \\ Batur Kanar: 0000-0002-5156-0302 \\ Hakki Kaya: 0000-0001-5230-635X \\ Fady Gerges: 0000-0002-8813-119X \\ Yusuf Çekici: 0000-0002-4585-3707 \\ Arash Hashemi: 0000-0002-5950-7266
}

\begin{abstract}
Bilal Çuğlan: 0000-0003-0581-4946 Lüttü Bekar: 0000-0002-3920-1382 Irina Kotlar: 0000-0002-1088-188X

Mustafa Yenerçağ: 0000-0002-0933-7852 Mesut Gitmez: 0000-0003-1078-9095

Aysel Akhundova: 0000-0002-4066-6822 Sinan Inci: 0000-0002-4576-128X Mehtap Yeni: 0000-0003-1647-5011 Mustafa Doğduş: 0000-0002-3895-1923 Meltem Altinsoy: 0000-0002-3494-5999 Shafa Shahbazova: 0000-0002-6695-1584 Fatih Tamnik: 0000-0003-2029-6630

Patrick W. J. Tiau: 0000-0002-0486-7600 İbrahim Ersoy: 0000-0002-3900-0097

Fadime Bozdurman: 0000-0003-0536-4666 Mehdi Zoghi: 0000-0002-0988-7061
\end{abstract}

Received: 30-12-2020 Revised: 08-03-2021 Accepted: 25-03-2021 Published Online: 05-07-2021

\begin{tabular}{|l|l|}
\hline \multicolumn{3}{|c|}{ Access this article online } \\
\hline Quick Response Code: & Website: \\
& \\
&
\end{tabular}

Address for correspondence: Dr. Tuğba Kemaloğlu Öz, Ulus Ahmet Adnan Saygun Cad, Canan Sk., 34340 Beşiktaş, Istanbul,

Turkey.

E-mail: tugbakemalogluoz@gmail.com

This is an open access journal, and articles are distributed under the terms of the Creative Commons Attribution-NonCommercial-ShareAlike 4.0 License, which allows others to remix, tweak, and build upon the work non-commercially, as long as appropriate credit is given and the new creations are licensed under the identical terms.

For reprints contact: WKHLRPMedknow_reprints@wolterskluwer.com

How to cite this article: Öz TK, Kivrak T, Almaghraby A, Abdelnabi M, Taşar O, Uygur B, et al. Demographic, clinical characteristics and medications of rehospitalized patients for acute coronary syndrome: Boomerang study. Int J Cardiovasc Acad 2021;7:45-9. 


\section{Abstract}

Background: Rehospitalizations with acute coronary syndromes (ACSs) have declined over the last years, but there is a remaining need for potential further reduction of rehospitalization after ACS to determine the most predominant predictors that can guide strategies to reduce re-hospitalizations burden. Aim: This multi-center study aimed to evaluate the demographic, clinical characteristics, and medications of rehospitalized patients who suffered a new cardiac event in 12 months after admission due to ACS. Material and Methods: Patients age $>18$ years who have been hospitalized between November 1 2017, and April 1 2018, for ACS within 12 months before the readmission for a new acute coronary event were enrolled. Results: The present study included a total of 628 (65.9\% from Turkey) consecutive patients rehospitalized with ACS (ST-elevation myocardial infarction [STEMI], 23.0\%; ACS without ST-elevation [NSTE-ACS], 76.9\%) from 15 different countries. The majority of the rehospitalized patients were men $(67.9 \%)$, and the mean age was $63.1 \pm 12.53$ years. $406(64.6 \%)$ had typical, 209 (33.2\%) of patients had atypical chest pain and $13(2.07 \%)$ had not any chest pain complaint during readmission. 304 (48.41\%) of patients were discharged from hospital earlier than 3 days and 107 (17.04\%) of patients stayed more than 7 days. The subcategories of first index diagnosis were 227 (36.1\%) STEMI; 401 (63.8\%) NSTE-ACS. The mean time from index discharge to rehospitalization was $189.25 \pm 118$ days. 248 (39.4\%) patients were re-hospitalized more than once after index discharge. The most common risk factors were diabetes mellitus (471, 75.0\%). 175 (27.87\%) of patients stopped taking medication before re-hospitalization. Most of the patients (69.4\%) had multivessel disease. Conclusion: Several factors identify patients at higher risk of rehospitalization with ACS. Understanding and preventing these causes can prevent rehospitalization and improve their outcome.

Keywords: Acute coronary syndrome, clinical characteristics, demographics, medication, rehospitalization

\section{INTRODUCTION}

Coronary artery disease (CAD) is the leading cause of death worldwide. Although there is a reduction in acute coronary syndrome (ACS) mortality over the last decades, its frequency is still increasing. ${ }^{[1]}$ Ischemic heart disease now accounts for almost 1.8 million annual deaths, or $20 \%$ of all deaths in Europe, even with large variations between countries. ${ }^{[2,3]}$ Re-hospitalizations for recurrent ACS after an acute myocardial infarction (AMI) are not only having high mortality rate ${ }^{[4]}$ but also may affect the psychology of the patients negatively. However, rehospitalization is associated with increased financial burden on both patients and health care system. ${ }^{[5]}$ Although some proportion of the rehospitalizations after ACS may be preventable by improved pre- and post-discharge patient care system, a certain percentage is not avoidable and usually related to the first admission. ${ }^{[6]}$

While late readmissions ( $>30$ days) have been related to disease-specific risk factors, early readmissions can effectively reflect the quality of care received. ${ }^{[7]}$

Recent data suggest that re-hospitalizations with ACS have declined over the last years, ${ }^{[8]}$ but there is a remaining need for potential further reduction of rehospitalization after ACS to determine the most predominant predictors that can guide strategies to reduce re-hospitalizations burden. Furthermore, few data are known about the potential variation and rates of rehospitalization around the world.

This multi-center study aimed to evaluate the demographic, clinical characteristics, and medications of rehospitalized patients who suffered a new cardiac event in 12 months after admission due to ACS. The study includes patients from fifteen different countries.

\section{Materials and Methods}

Patients age $>18$ years who have been hospitalized between November 1 2017, and April 1 2018, for ACS within 12 months before the readmission for a new acute coronary event(ST-elevation myocardial infarction [STEMI], non-ST-elevation myocardial infarction [NSTEMI]) were enrolled in the study. The ACS index hospitalization was defined as the first ACS hospitalization before the readmission. Patients hospitalized with a principal diagnosis of ACS, ACS without ST-elevation (NSTE-ACS) (including NSTEMI and unstable angina), or STEMI will be identified from admission records by using the (International Classification of Diseases 9-CM) diagnosis codes. Patients whose previous hospitalizations data are not available and/or according to The Universal Definition of Myocardial Infarction, Type 2 patients were excluded from the study. Patients are captured when they are re-admitted to the cardiac department with ACS. Physicians use prospective data collection via a structural case report form for patient's demographic and clinical characteristics including habits, comorbidities, previous medical history, family history, lifestyle, sociocultural level, and the details of treatment during the first admission when patients were captured. In addition, all clinical data, biochemical, electrocardiographic, and echocardiographic findings were obtained during rehospitalization.

SPSS software version 22.0 (SPSS Science, Chicago, IL, USA) was used for statistical analysis. Numeric variables were expressed as mean \pm standard deviation (SD). In the descriptive analysis of data, means, SD, and percentages were used. Differences in categorical variables between groups were tested using an independent sample $t$-test and the Mann-Whitney U-test, as appropriate. A $P<0.05$ was considered statistically significant. Pearson correlation analysis was used to evaluate the association between variables.

\section{Ethical statement}

Approval of the Institutional Ethical Committee was obtained for the study protocol, and informed consent was obtained from all patients. 


\section{RESULTS}

The present study included a total of 628 (65.9\% from Turkey) consecutive patients re-hospitalized with ACS (STEMI, 23.0\%; NSTE-ACS, 76.9\%) from 15 different countries. The distribution of countries that patients came from is shown in Figure 1 . The majority of the rehospitalized patients were men $(67.9 \%)$, and the mean age was $63.1 \pm 12.53$ years. Among the patients, the proportion of university graduates was $8 \%$ and $28 \%$ of patients had never been to school.

Four-hundred and six (64.6\%) had typical, 209 (33.2\%) of patients had atypical chest pain and $13(2.07 \%)$ had not any chest pain complaint during readmission. Eighteen patients were re-admitted to the hospital with cardiogenic shock. In-hospital mortality was $2.07 \%$ (13 patients). Three hundred and four $(48.41 \%)$ of patients were discharged from hospital earlier than 3 days and $107(17.04 \%)$ of patients stayed more than 7 days. The subcategories of first index diagnosis were 227 (36.1\%) STEMI; 401 (63.8\%) NSTE-ACS. The mean time from index discharge to rehospitalization was $189.25 \pm 118$ days. 248 (39.4\%) patients were rehospitalized more than once after index discharge.

The most common risk factors were diabetes mellitus (471, $75.0 \%)$ and second hypertension $(466,74.2 \%)$ among rehospitalized patients. 255 (40.6\%) of patients were current smokers and $216(34.4 \%)$ were former smokers. Despite 307 (48.89\%) of patients had dyslipidemia, only 114 (18.15\%) of patients followed the diet that ESC recommended and just $270(42.99 \%)$ of them were doing mild-to-moderate physical activity. The distribution of risk factors is summarized in Table 1.

Unfortunately, 175 (27.87\%) of patients stopped taking medication before re-hospitalization. Only 414 (65.9\%) of patients were using acetylsalicylic acid, 409 (65.13\%) clopidogrel, $80(12.74 \%)$ ticagrelor, and $6(0.96 \%)$ prasugrel. 500 (79.62\%) of patients were using B-blockers, 246 (39.17\%) angiotensin-converting enzyme inhibitors, 155 (24.68\%) angiotensin-receptor blockers, 444 (70.7\%) statins, 10 (1.59\%) warfarin, and 35 (5.57\%) direct oral anticoagulants.

The mean left ventricular ejection fraction was $50.64 \% \pm 11.56 \%$, 148 (23.57\%) and 164 (26.1\%) of patients had heart failure and valvular heart disease, respectively. Most patients (95.38\%)

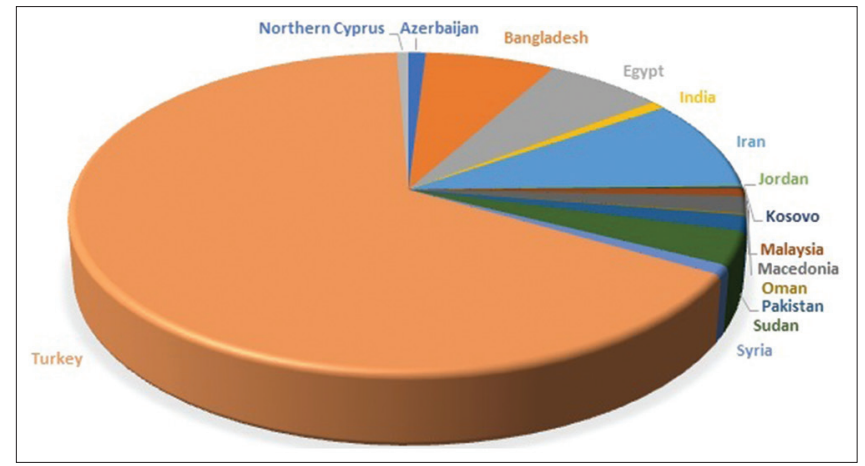

Figure 1: The distribution of countries that patients came from had normal sinus rhythm, 28 (4.46\%) had atrial fibrillation and only one $(0.16 \%)$ had a pacemaker. The mean heart rate was $80.6 \pm 13.32 / \mathrm{min}$.

However, $576(91.7 \%)$ of patients underwent coronary angiography during rehospitalization and $17.0 \%$ of them received only medical treatment. Most of the patients (69.4\%) had multivessel disease.

On the other hand, cardiac percutaneous coronary interventions were performed in $68.7 \%$ of patients and $5.8 \%$ of patients who underwent coronary artery bypass surgery. Fibrinolytic therapy was applied just to $49(7.8 \%)$ of patients.

\section{Discussion}

This multi-center study provided several important insights into the phenomenon of rehospitalization after ACS discharge in 15 different countries.

In 2012, Sangu et al.$^{[8]}$ analyzed data from 5219 patients with an ACS enrolled in the Australian and New Zealand and found that $(1048,20.1 \%)$ of ACS patients were readmitted again within 6 months of discharge with a significant proportion of them (41.4\%) occurring within 30 days of discharge. And according to Sangu, recurrent ischemia in hospitals and the diagnosis of STEMI during the index admission were associated with the strongest risk of early rehospitalization. This finding was in contrary to our findings where the majority of the rehospitalizations were for patients presented initially with the diagnosis of NSTE-ACS (72.45\%).

Then in 2014, Southern et al. ${ }^{[9]}$ studied the patients admitted with an ACS hospitalization between April 2008 and March 2010 in one of the USA provinces and he analyzed the

\begin{tabular}{lc}
\hline $\begin{array}{l}\text { Table 1: The distribution of risk factors associated } \\
\text { with re-hospitalization in patients with acute coronary } \\
\text { syndromes }\end{array}$ \\
\hline Risk factors & $\boldsymbol{n}(\%)$ \\
\hline Hypertension & $466(74.2)$ \\
Diabetes & $471(75.0)$ \\
Dyslipidemia & $307(48.89)$ \\
PAD & $68(10.83)$ \\
Current smoker & $255(40.61)$ \\
Former smoker & $216(34.4)$ \\
Mild to moderate physical activity & $270(42.99)$ \\
Depression & $88(14.01)$ \\
Family history of CAD & $121(19.27)$ \\
Current alcoholic & $27(4.3)$ \\
Past alcoholic & $93(14.81)$ \\
Lung disease & $49(7.8)$ \\
Heart failure & $148(23.57)$ \\
Active malignancy & $8(1.27)$ \\
ESC recommended diet & $114(18.15)$ \\
Low salt consumption & $82(13.06)$ \\
\hline CAD: Corony arty
\end{tabular}

CAD: Coronary artery disease, ESC: European Society of Cardiology, PAD: Peripheral artery disease 
readmissions at 1 month and 1 year and he found that $34.3 \%$ of patients had $\geq 1$ hospital readmission within 30 days, reaching $61.7 \%$ within 1 year of ACS discharge. Of first readmissions, $45 \%$ were emergency department only and 53\% were for cardiovascular or possibly related diagnoses. Renal disease and diabetes predicted all-cause readmissions at 30 days and 1 year which was partially the same to what we have found in our study where the most prevalent risk factor was diabetes $(75 \%)$ followed by hypertension (63.85\%).

In 2015, Arnold et al. studied the rates and predictors of re-hospitalizations for ACS and revascularization within the year after AMI among 3283 patients and he found that the strongest predictors of rehospitalization for ACS were coronary artery bypass graft before AMI hospitalization (hazard ratio [HR] 2.12, 95\% confidence interval [CI] 1.45-3.10), female sex (HR 1.67, 95\% CI 1.23-2.25), and in-hospital percutaneous coronary intervention (PCI) (HR 1.85, 95\% CI 1.28-2.69). ${ }^{[10]}$ This finding contradicted what we found in our study, where most of the readmitted patients were only hospitalized once $(60.51 \%)$ and most of them were NSTE-ACS (63.85\%) with a male predominance $(67.99 \%)$.

Lam et al. ${ }^{[11]}$ in 2018 studied the gender differences in rehospitalization in patients with index hospitalizations with the diagnosis of ACS who underwent PCI. There were 58330 -day readmissions in this study ( $11 \%$ of subjects). The readmission rate for women was $13.9 \%$, compared to $9.6 \%$ for men $(P<0.0001)$ and they found out that the mean age was older than that of men and women have a higher 30-day readmission rate compared with men in all age ranges. Their numbers were almost similar to ours where we had $32.01 \%$ of females in readmission after ACS.

Finally in 2019, Oliveira et al. ${ }^{[12]}$ studied the readmission rates in patients with ACS and its determinants and they included 536 patients and they found that $21.5 \%$ of them were readmitted within 1 year. Regarding the reasons of hospital readmissions, $42.6 \%$ were ACS, 20.9\% were with other cardiovascular causes and $36.52 \%$ were admitted due to other noncardiovascular causes. According to Oliveira et al., readmission rates were higher in patients with STEMI, dyslipidemias, chronic kidney disease, congestive heart failure, angina, AMI, and previous angioplasty. In addition, according to our data, this study partially agreed with ours where most predictors were diabetes $(75 \%)$ followed by hypertension (63.85\%) and smoking (40.61\%).

Oliveira et al.${ }^{[12]}$ found that the absence of statin after the ACS event was associated with re-hospitalization. In our study, $27.87 \%$ of patients stopped taking all cardiac medication before rehospitalization and only $70.7 \%$ of patients were taking statins treatment during rehospitalization.

To the best of our knowledge, this is the largest and first descriptive study that incuded fifteen countries. Different risk predictors of rehospitalization after ACS have been described in the literature. This difference might be explained by different characteristics of the study populations, and particularities of health care systems, or dissimilar study designs. The high re-hospitalizations rates show the importance of developing new strategies during hospitalization, at and after discharge, to reduce the number of re-hospitalizations.

\section{Limitations}

The study had several limitations. Although our study is a multi-center descriptive study, there is not enough number of patients to compare the data of each country, separately. On the other hand, our data are comprised a large multiethnic population. Furthermore, the patient's risk factors for CAD were derived from the re-hospitalizations, which may not necessarily reflect the patient's risk factors on the first admission. However, the most important risk factors present at rehospitalization are chronic conditions that are likely present on index admission as well. Further research into the unmeasured causes for this difference is needed.

\section{Conclusion}

Several factors identify patients at higher risk of rehospitalization with ACS. Understanding and preventing these causes can prevent rehospitalization of high-risk patients and improve their outcomes.

\section{Declaration of patient consent}

The authors certify that they have obtained all appropriate patient consent forms. In the form the patients have given their consent for their images and other clinical information to be reported in the journal. The patients understand that their names and initials will not be published and due efforts will be made to conceal their identity, but anonymity cannot be guaranteed.

\section{Financial support and sponsorship}

Nil.

\section{Conflicts of interest}

There are no conflicts of interest.

\section{RefEREnCES}

1. Hartley A, Marshall DC, Salciccioli JD, Sikkel MB, Maruthappu M, Shalhoub J. Trends in mortality from ischemic heart disease and cerebrovascular disease in Europe: 1980 to 2009. Circulation 2016;133:1916-26.

2. Townsend N, Wilson L, Bhatnagar P, Wickramasinghe K, Rayner M, Nichols M. Cardiovascular disease in Europe: Epidemiological update 2016. Eur Heart J 2016;37:3232-45.

3. Gaziano TA, Bitton A, Anand S, Abrahams-Gessel S, Murphy A. Growing epidemic of coronary heart disease in low- and middle-income countries. Curr Probl Cardiol 2010;35:72-115.

4. Belitardo JN, Ayoub AC. Identification of re-admission predictors in elderly patients with acute coronary syndrome. Int J Cardiovasc Sci 2015;28:139-47.

5. Berenson K, Ogbonnaya A, Casciano R, Makenbaeva D, Mozaffari E, Lamerato L, et al. Economic consequences of ACS-related rehospitalizations in the US. Curr Med Res Opin 2010;26:329-36.

6. van Walraven C, Bennett C, Jennings A, Austin PC, Forster AJ. Proportion of hospital readmissions deemed avoidable: A systematic review. CMAJ 2011;183:E391-402. 
7. Aliprandi-Costa B, Ranasinghe I, Chow V, Kapila S, Juergens C, Devlin G, et al. Management and outcomes of patients with acute coronary syndromes in Australia and New Zealand, 2000-2007. Med J Aust 2011;195:116-21.

8. Sangu PV, Ranasinghe I, Aliprandi Costa B, Devlin G, Elliot J, Lefkovitz J, et al. Trends and predictors of rehospitalisation following an acute coronary syndrome: Report from the Australian and New Zealand population of the Global Registry of Acute Coronary Events (GRACE). Heart 2012;98:1728-31.

9. Southern DA, Ngo J, Martin BJ, Galbraith PD, Knudtson ML, Ghali WA, et al. Characterizing types of readmission after acute coronary syndrome hospitalization: Implications for quality reporting. J Am Heart Assoc 2014;3:e01046.

10. Arnold SV, Smolderen KG, Kennedy KF, Li Y, Shore S, Stolker JM, et al. Risk factors for rehospitalization for acute coronary syndromes and unplanned revascularization following acute myocardial infarction. J Am Heart Assoc 2015;4:e01352.

11. Lam L, Ahn HJ, Okajima K, Schoenman K, Seto TB, Shohet RV, et al. Gender differences in the rate of 30-day readmissions after percutaneous coronary intervention for acute coronary syndrome. Womens Health Issues 2019;29:17-22.

12. Oliveira LM, Costa IM, Silva DG, Silva JR, Filho JA, Santos MA, et al. Re-admission of patients with acute coronary syndrome and determinants. Arq Bras Cardiol 2019;113:42-9. 